\title{
Monitoring Soil Moisture Consumption in Guilan Province
}

\author{
Jalal Behzadi $^{1}$ \\ ${ }^{1}$ Assistant Professor and Faculty Member of Islamic Azad University, Lahijan Branch
}

\begin{abstract}
Two elements, i.e. atmospheric precipitation and environmental temperature are the main parameters of water balance. Water balance may cause water resource shortage, water surplus, and therefore soil moisture consumption. Soil moisture consumption strengthens and weakens along with water shortage and surplus oscillations. In the present study, first the statistics regarding the precipitation and temperature of four climatic stations naming Rudkhan Castle, Lahijan, Shanderman and Manjil were closely monitored, and the water balance diagram was illustrated for these chosen stations. In the present diagram for these selected stations, it can be observed that soil moisture consumption decreases with an increase in water surplus and turns pink; and it increases with a decrease in water surplus or water shortage. Although soil moisture consumption is felt in most cases, but with an increase in water shortage, soil moisture consumption increases more and more. Especially, considering the level of climatic variety present in Guilan, the more a moist climate changes towards dry, such as Manjil, we would witness more decrease or even elimination of water surplus, and soil moisture consumption increases as a result of this water shortage. Therefore, climatic type has the most significant impact on soil moisture consumption. Despite climatic conditions, soil type, contexture, and vegetation have an impact on the water capacity present in soil. Then soil moisture consumption has been calculated, especially in the critical section, and soil moisture consumption distribution in Guilan province was determined accordingly. Knowing the water balance, especially the moisture present in soil and soil moisture consumption are necessary parameters in planning all over the world.
\end{abstract}

Keywords: precipitation, soil,guilan, GIS

\section{Introduction}

With no doubt, knowing the amount of moisture present in soil and soil moisture consumption in monthly or annual periods is considered as one of the most important issues in the world, especially in agriculture section, which requires a great deal of attention.

The water present in soil can be generally divided in three main categories: gravitational, capillary and Hygroscopic. It must be noted that soil moisture in Geotechnical engineering is defined as "that part of the free water which fills the pore spaces and is known as pore water or gravitational water. The most important environmental factor affecting the compression of agricultural soils while tillage operation is soil moisture. Spoore and Godwin (1978) believe the desirable moisture for tillage operations is lower than the Plastic Limit (PL) of the soil. Allmaras et al. (1987) suggested that this moisture is in moisture domain of 0.9 of plastic limit in silt loam, clay loam and loam soil textures. Pliusnin (1970) considers this moisture equal to $40 \%$ of porosity. Based on the results presented by Ghuman and R. Lal (1992), soil moisture can be an important factor in relation with compression, even while harvesting. With an increase in moisture, soil compression increases as a result of tractor passing, and it will have the highest compression at the critical moisture point. Based on Allmaras, soil compression is significant and considerable when porosity drops below 10\%, since this may affect microorganism activity. These researches have been conducted in European and North American countries. Soil moisture can be modeled using finite element methods. The compressibility of soils depends on clay percentage.

Taylor conducted some research on developing cotton root in various soils. He concluded that root development decreases significantly with an increase in soil compression, even in a slight degree. The most significant consequence of excessive increase in soil compression is the reduction of crop performance. The results of the study by Mc. Keys which has been conducted in four consecutive years (1976-1980) on fodder 
maize indicate that compression increase in low degrees leads to an increase in crop performance, but if soil compression increases more than a specified level, it significantly leads to a decrease in crop performance. The major indices used to express this condition include drought, Torrent white index, Torrent white water balance model, and the Palmer index. The latter index is one of the most important methods of studying drought by calculating water balance. Synoptically analysis methods for dynamically studying drought have not attracted a significant attention. Iran is a vast country which possesses various climates due to unique conditions and characteristics and topography. A comparison on water balance parameters in traditional and flattened agricultural fields in Qaem Shahr County was conducted by Milad Babapoor, Golafshani et al. Rice is the second most important crop in the world after wheat, and Iran possesses a special position in this regard by producing about two million tons of rice each year. Considering the drought crisis and high consumption of water in rice fields, finding solutions for increasing irrigation productivity can be so helpful. It can be concluded that a $25 \%$ decrease in depth penetration parameter in flattened fields compared to traditional ones leads to a $10 \%$ increase in irrigation productivity.

\section{Material Method}

\section{The Geography of Guilan Province and the Measuring Stations}

Guilan is located in the north of country in the longitude of 50.35 to 48.32 and in the latitude of 38.27 to 33.36. It neighbors the Caspian Sea on the north, Mazandaran province on the east, Qazvin province on the south, and Azerbaijan and Ardabil provinces on the west. The area of the province equals 13790.5 square kilometers and it is made up of three geographical areas: plains, foothills and mountainous areas. 29\% of the land is agricultural, $41 \%$ forestall, and $16 \%$ for pastures. The plain area includes the two areas of Talesh and Shafa Rud plain to the east of Kelachay. Talesh, Tarom-Khalkhal, and Deylaman mountains are the three mountain ranges surrounding the province.

TABLE I: Geographical and climatic conditions of Guilan province stations

\begin{tabular}{ccccc}
\hline \hline Station & Longitude & Latitude & Altitude & Average Precipitation \\
\hline Manjil & 49.26 & 37.28 & -26.8 & 1745.4 \\
Lahijan & 50 & 37.12 & 34.2 & 1049.1 \\
Rudkhan Castle & 49316 & 37.06 & 170 & 1683.9 \\
Shanderman & 49.09 & 37.27 & 42 & 974 \\
\hline \hline
\end{tabular}

\section{The Climate of the Stations}

Among all the selected stations, the west of the province including Rudbar and Manjil possesses a different climate compared to the other areas, and there is a significant difference considering the obtained patterns such as average precipitation. Almost all the stations have regional characteristics with warm and humid summers and wet and moderate winters. Plain stations possess a rain forest and very wet climate, but Manjil is of semidry and step climate type.

\section{Soil Moisture (Soil Moisture Consumption)}

A portion of precipitation is cumulated and absorbed by buildings and plants and trees. This portion often evaporates and returns to the atmosphere. Another portion penetrates into the ground and creates groundwater currents or water lavers. The evaporation in various parts goes back into the atmosphere in the form of humidity and returns to the ground once more in the form of precipitation.

Keeping the above mentioned information in mind, water balance has been studied in four stations of Guilan province which were picked out based on precipitation index in clustering method, including Manjil, 
Shanderman, Lahijan, and Rudkhan Castle. The soil capacity is about 200 millimeters and lower in some regions. Keep in mind that Torrent White measured soil moisture capacity as 300 and drought as 200 millimeters in New Jersey which is a humid region, and this indicates a low water capacity in the studied soils (Guilan). The highest water shortage occurred in June as 11.69 and its lowest amounts belong to wet months until May. The highest water surplus occurs in October and equals 159.75 and its lowest is observed in august and equals zero. The highest runoff occurs in December as 113.86 and its lowest is 7.11 millimeters in august. Also, water shortage in this station is less than the other ones. Water crisis occurs in the months of July and August, and there is a good water balance from March until May.

TABLE II: data from Lahijan station water balance

\begin{tabular}{ccc}
\hline \hline & High & Low \\
\hline TC & August 24.93 & February 6.9 \\
I & August 11.37 & January 1.63 \\
UP & July 3.9 & February and March 0.5 \\
PE & July 146.25 & February 12.9 \\
P & October 216.4 & August 35.46 \\
$\mathrm{P}-\mathrm{PE}$ & December 159.65 & August 35.7 \\
$\mathrm{ACC}$ & August -274.6 & April 0 \\
$\mathrm{St}$ & Wet months (April) +200 & August 50 \\
$\Delta$ st & August -47 & Wet months (April) 0 \\
$\mathrm{AE}$ & July 107.7 & February 12.9 \\
$\mathrm{D}$ & August 65.92 & April 0 \\
$\mathrm{~S}$ & December 159.6 & Dry months (August) 0 \\
$\mathrm{RO}$ & February 234.7 & September 3 \\
\hline \hline
\end{tabular}

The highest runoff equals 234.7 millimeters in February and the lowest is 3 millimeters in September. The most serious water crisis and soil moisture consumption is observed in July and the least serious is from February until May.

TABLE III: data from Manjil station water balance

\begin{tabular}{ccc}
\hline \hline & High & Low \\
\hline TC & August 27 & \\
$\mathrm{I}$ & August 12.92 & February 7.4 \\
$\mathrm{UP}$ & July and August 4.5 & February 1.61 \\
$\mathrm{PE}$ & July 168.75 & February 0.4 \\
$\mathrm{P}-\mathrm{PE}$ & March 44 & August -155.75 \\
$\mathrm{ACC}$ & October -898.7 & February 0 \\
$\mathrm{St}$ & March 70 & November 2 \\
$\Delta \mathrm{st}$ & February 23.41 & -30 \\
$\mathrm{AE}$ & July 33.15 & February 10.32 \\
$\mathrm{D}$ & August 149.7 & March and wet months \\
$\mathrm{S}$ & February 23.4 & October and November 0 \\
$\mathrm{RO}$ & February 15.7 & September 0.3
\end{tabular}

The highest temperature is in August, the highest water crisis in July and August, and the lowest is seen in February and March. It should be noted that in monitoring the water balance of the 4 stations, it was found out that the highest variation in water balance items belongs to Manjil which is highly different with other stations.Based on the estimated diagram using Torrent white, the obtained results indicate that Shanderman after Manjil possesses the lowest water potential among the stations of Guilan, and it also holds the first rank in plain areas based on the obtained clustering, Lahijan holds the second and Rudkhan Castle holds the third rank. Based on the diagram, the most serious water shortage in the plain is for Shanderman and the least serious one is observed in Lahijan. The highest soil moisture consumption is in Shanderman and its lowest is in Rudkhan Castle. The highest water surplus is observed in Rudkhan Castle which along with Lahijan continues until May. Water shortage in Shanderman starts from around April $15^{\text {th }}$, but in Lahijan and Rudkhan Castle stations it starts 
after May. It should be pointed out that there is a water crisis in all the stations in August and September, but in Shanderman it can also be observed in July as well. But this station has a more proper water balance condition from March until May. What we can say for sure is that these stations possess relatively various water potentials. Considering the very low water potential of Manjil, it can be seen that it possesses the highest water shortage and soil moisture consumption and the lowest water surplus. If we take a field view look at the natural environment of Manjil, the very low water potential can be observed along with the very weak vegetation. This itself is another reason for distinguishing Manjil from other plain stations of Guilan.

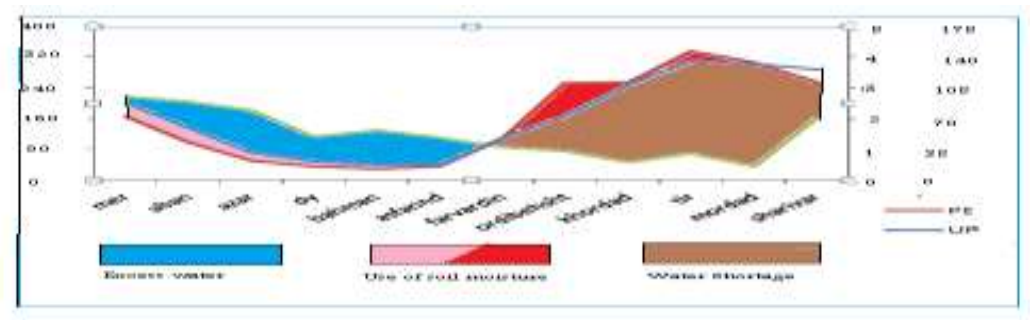

Fig. 1: Water balance (soil moisture consumption) diagram of Lahijan station

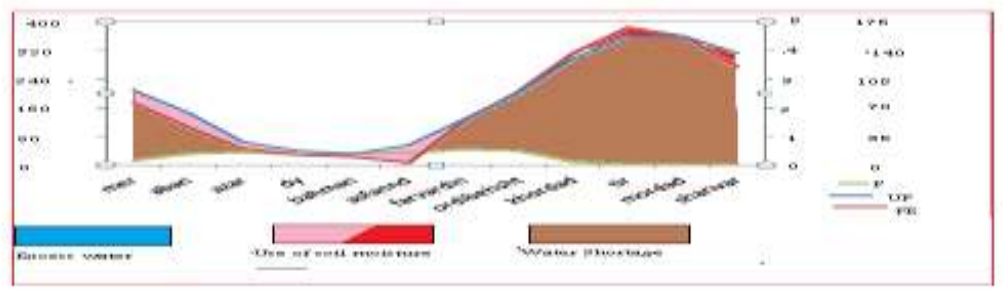

Fig. 2: Water balance (soil moisture consumption) diagram of Manjil station

Low soil capacity, especially in plain areas causes a considerable water increase after every heavy precipitation. Moreover, the reason for the weakness of water resources in dry years can be found in it. The destruction of environment, lands change of application, destruction of forests, making farms and destroying them again, destroy the soil. With destruction of soil humus and water absorbent materials, the soil of plains is continuously exposed to erosion. Building cities and towns leads to the weakening of soil minerals and more acidification of it. It is obvious that the more climate tends from humid moderate to semi-dry and dry, there would be less water surplus and more water shortage. With an increase in water shortage, soil moisture consumption increases as well. Soil moisture consumption is of different grades in the stations of Guilan. These differences were obtained and ranked based on the numeral data, distribution and soil moisture consumption regions in Guilan province.

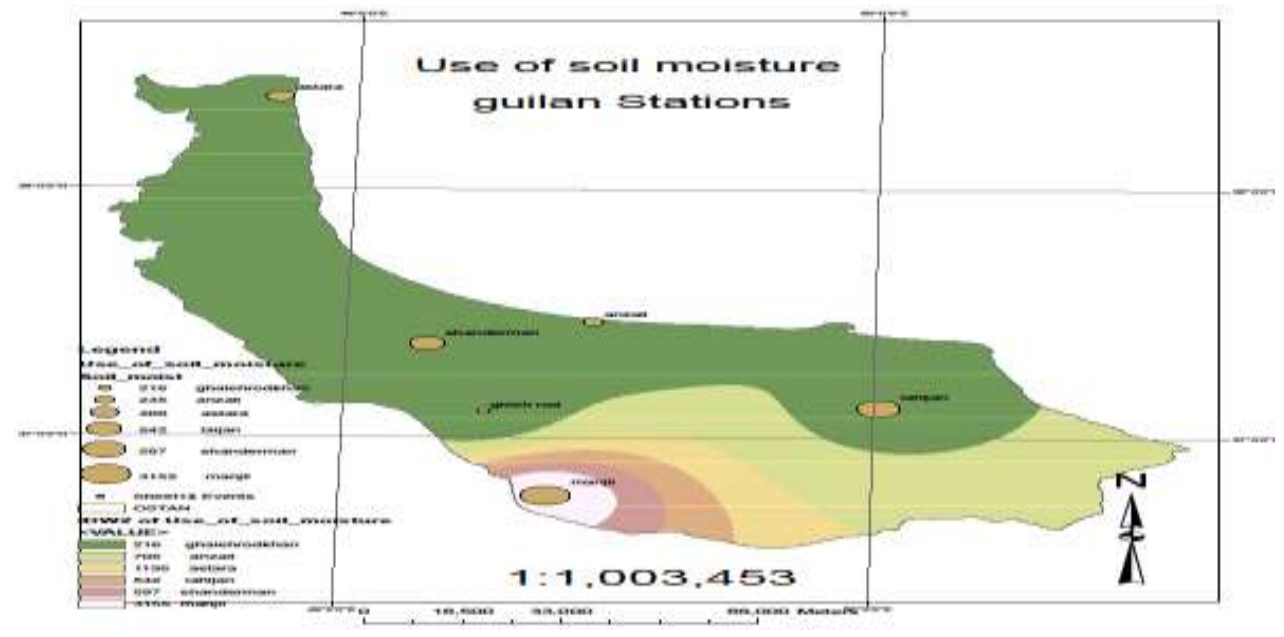

Fig. 3: distribution of soil moisture consumption 
According to the illustrated map, the ranking of various stations based on water potential weakness and soil moisture consumption is as follows: Manjil, Shanderman, Lahijan and Rudkhan Castle.

\section{Conclusion}

Studying water balance is one of the centers of attention for climatologists and hydrologists. It plays a considerable role in the environment, sustainable development, management of water resources, and optimized environmental, economic and agricultural planning. In the present study, the focus has been on including average long-term behavior (variations) and oscillations (variability) of monthly elements such as precipitation, and balanced and unbalanced evaporation, and eventually obtaining the water remaining in soil, water shortage, water surplus and runoff. Guilan province is much more distinguished in agriculture and tourism sectors compared to other ones. For instance, the difference between dry farming and aquiculture lies in their planning. In dry farming, the seeds are planted and irrigation is left in hands of fortune and of course past experiences and precipitation trends. On the other hand, in aquiculture the exact amount of water needed by the land can be estimated using proper water management through building dams and controlling wandering waters. It looks obvious that aquiculture produces better results due to the planning of water requirements. Some of the most important factors which affect the climate of the province are the heights, moisture resources of the Caspian Sea, water currents in the east and west, drainage basin of lagoons and ponds, free waters, and air current systems entering the province. The hydrological condition of the province is in such a way that precipitation water depletion can always be observed and this has a significant impact on the climate and microclimate of the province. The morphological condition and its severe changes have a clear impact on the climatic variation of the province. Variable climate resulting from three different mountainous, plain and foothill areas has led to a variety in agriculture. Wet and dry years occur for different reasons and in various forms. A dry year might be climatic, economic, agricultural or hydrological. Guilan province is located in a semi-dry area, but due to the easy entrance of systems, especially wet moderate types and also the presence of the heights, there is a humid climate in it. In evaluating average precipitation using the Thiessen method, it was found out that 13 chosen stations have a precipitation of 1070 millimeters with and 11138 millimeters without Manjil station. The climate of Manjil is of moderate and humid type, but it should be noted that with man-made and natural pressures and land application changes and environmental crises, the climate might change again and return to its initial condition, and this can lead to an imbalance in climatic elements such as precipitation and temperature. In order to focus the studies and obtaining proper results, clustering method has been used, and five stations naming Rudkhan Castle, Lahijan, Shanderman, and Manjil were picked out of thirteen stations. Soil moisture consumption in the stations of Guilan is of various degrees, and rankings, distribution and its regions were obtained based on it. Due to the climatic variations, we can witness a variation in water potentials which leads to bio variations in water balance. In average, the stations of Guilan have a high water requirement from April to November. Low soil capacity, especially in plain areas leads to an increase in the volume of runoff after heavy precipitations. The reason for severe shortage of water resources ion dry years can be found here. The highest moisture consumptions are found in Manjil, Shanderman, Lahijan and Rudkhan Castle. As mentioned earlier, Manjil varies from other stations from climatic and geographical points of view with a more serious water shortage and soil moisture consumption crisis, and Shanderman station holds the first rank of water shortage and soil moisture consumption crisis in plain areas and the second rank in whole Guilan, after Manjil. The two stations of Lahijan and Rudkhan Castle are in better conditions. Soil humus and water holding materials in soil are bein continuously eroded due to lands application change, creating farms and destroying them again, building cities and towns, and this leads to the weakening of minerals and more acidification in soil. Planting more sustainable species such as deciduous trees and evergreen local trees except Coniferae, using urban and suburban water reservoirs, building small dams, natural and artificial pools, and injecting surface and precipitation waters are some of the things that should be done in Guilan in order to conserve water resources and increase soil moisture, and minimize soil moisture consumption. 


\section{Reference}

[1] V. Portoghese, M.Uricchio, and A. Vurro.(2005) .GIS tool for hydro geological water balance evaluation on a regional scale in semi-arid environments.Computers \& Geosciences, $\quad$ Volume $31 \quad$ Issue 1. Available:DOI=http://dl.acm.org/citation.cfm?id=1650421.1650706

[2] D.Roy, N. Panda, and B. Panigrahi.(2009). Water balance simulation model for optimal sizing of on-farm reservoir in rain fed farming system .Computers and Electronics in Agriculture, Volume 65 Issue 1. DOI=//http://dl.acm.org/citation.cfm?id=1478661.1478758

[3] W. D. Welsh .(2008).Water balance modeling in Bowen, Queensland, and the ten iterative steps in model development and evaluation .Environmental

Software,Volume23,Issue2.DOI=//http://dl.acm.org/citation.cfm?id=1294367.1294467

http://dx.doi.org/10.1016/j.envsoft.2007.05.014

[4] H.,Li,R., Zhang, Q.Yang, T.,Li,L. McVicar, and Q. Liu.(2009). Integration of a Water Balance Model with a Decision Support Tool in the Loess Plateau of China .International Forum on Information Technology and Applications Volume 01 , Volume 01 .DOI=//http://dl.acm.org/citation.cfm?id=1606748.1606921

[5] L. Dexter, and ch .Avery. (1991).Using spreadsheet software in water-balance modeling .Computers \& Geosciences, Volume 17 Issue 4. DOI=//http://dl.acm.org/citation.cfm?id=108437.108441

http://dx.doi.org/10.1016/0098-3004(91)90111-P

[6] D.Wan, J.Tang, D.Yu, and X.Guan,(2012). Research on scientific data sharing platform of hydrology and water resources based on service composition. Computers \& Geosciences archive .Volume 31 Issue 1.DOI:http://dl.acm.org/citation.cfm?id=1650421.1650706

[7] Z.Yin, T.Lei, Q.Yan, , Z. Chen, and Y.Dong.(2013) .A near Computers and Electronics in Agriculture -infrared reflectance sensor for soil surface moisture measurement. Volume 99 Issue Volume 99 Issue C .DOI: http://dl.acm.org/citation.cfm?id=2749492.2750254 